\title{
Experimental evidence about misconception of Terzaghi's 1-D consolidation theory in terms of degree of consolidation
}

\author{
Bartłomiej Szczepan Olek ${ }^{1, *}$ \\ ${ }^{1}$ Cracow University of Technology, Faculty of Civil Engineering, Krakow, Poland
}

\begin{abstract}
Terzaghi's 1-D consolidation theory is commonly used for prediction of embankment settlement in soft fine-grained soil. Application of this theory is not always effective due to the simplifications of assumed soil behavior under load. This paper examines relationship between the degrees of consolidation determined by pore water pressure measured at the base of the sample and one-dimensional strain. Theoretically, this relationship should be unique, however experimental relationships correlating the degrees of consolidation are found to be non-linear. The article presents the results of multistage consolidation tests with pore water pressure measurements, carried out on intact and reconstituted deep marine clay. Consolidation tests were conducted with uniform stress distribution and single-sided drainage conditions. It was observed that the relationship between degrees of consolidation for intact and reconstituted samples largely divergent from theoretical unique line.
\end{abstract}

\section{Introduction}

The effects of load applied on saturated cohesive soil can be observed as changes in the state of stress in both solid and liquid phases in proportion to their stiffness. Increase of pore water pressure and hydraulic gradients causes the water flow through the soil. Then the resulting excess pore water pressure is transferred on the soil skeleton as hydrostatic pressure. For well-permeable soils, the time required for the water flow and the end of the load transfer mechanism is so short that the solution to the problem is limited only to acquire the equilibrium state. In this case, the problem is time-independent. However, for fine-grained soils (like clays), the required time become significant and it is necessary to analyse the time-dependent stress-strain behavior [1-2]. In soil mechanics, this phenomenon is known as consolidation. This process involves drainage, compaction and stress transfer in time due to changes in the load. The permeability and compressibility behavior of finegrained soils, especially their time-dependency makes consolidation a very complex phenomenon subjected to continuous development [3-7].

In spite of many developments in this area, Terzaghi's One-dimensional Consolidation Theory [8] is most widely used theoretical description of this process. The use of a linear

* Corresponding author: bartlomiej.olek@pk.edu.pl 
stress-strain relationship to describe soil response to the load on which a theory is based, is associated with obtaining an inadequate characteristic of the soil behavior. As indicated by experimental observations behavior of fine-grained soils, due to their formation conditions and environmental influences should be considered as non-linear and anisotropic. In these work two methods for determination degree of consolidation, $U$ were used to describe consolidation behavior. According to theory, exist a relationship between degree of consolidation calculated based on observed one-dimensional strain - so-called average degree of consolidation, $U_{\varepsilon}$ and degree of consolidation at the base, $U_{u b}$, which describe unique strain development during pore water pressure dissipation.

In the work presented herein uniqueness of $U_{\varepsilon}-U_{u b}$ relationship was verified and assessed on the basis of experimental observations. Presented analysis is a part of preliminary investigation of strain development during dissipation of pore pressures under one-dimensional loading.

\section{Material and method}

In order to evaluate the Terzaghi's theory of consolidation and then consolidation behavior, tests on reconstituted and intact deep marine clay were performed (see Table 1). Some physical properties of the investigated soil is summarized in Table 2. The Krakowiec clay was formed in the north part of the Carpathian Foredeep of eastern Poland, situated $7 \mathrm{~km}$ south of Tarnobrzeg. The deposit is composed of an approximately several hundred $\mathrm{m}-$ thick firm clay. Raw clay material from Chmielów continues to be used in manufacturing of building brick.

Table 1. Test conditions of reconstituted and intact samples of Krakowiec clay.

\begin{tabular}{|c|c|c|c|c|c|}
\hline Test & Soil type & $\begin{array}{c}\text { Sample } \\
\text { conditions }\end{array}$ & Depth (m) & $\begin{array}{c}\text { Applied } \\
\text { pressure }(\mathrm{kPa})\end{array}$ & $\begin{array}{c}\text { Loading } \\
\text { conditions }\end{array}$ \\
\hline IK1 & $\begin{array}{c}\text { Krakowiec } \\
\text { clay }\end{array}$ & Reconstituted & $5.10-5.13$ & $300-900$ & 4 days \\
\hline IK2 & $\begin{array}{c}\text { Krakowiec } \\
\text { clay }\end{array}$ & Reconstituted & $5.10-5.13$ & $300-900$ & 4 days \\
\hline IK3 & $\begin{array}{c}\text { Krakowiec } \\
\text { clay }\end{array}$ & Reconstituted & $5.10-5.13$ & $300-900$ & 4 days \\
\hline IN1 & $\begin{array}{c}\text { Krakowiec } \\
\text { clay }\end{array}$ & Intact & $4.15-4.18$ & $300-900$ & 3 days \\
\hline IN2 & $\begin{array}{c}\text { Krakowiec } \\
\text { clay }\end{array}$ & Intact & $4.21-4.24$ & $300-900$ & 3 days \\
\hline
\end{tabular}

Table 2. Physical characteristics of intact Krakowiec clay.

\begin{tabular}{|c|c|c|c|c|c|c|c|c|}
\hline & \multicolumn{3}{|c|}{$\begin{array}{c}\text { Percentage of fraction } \\
\text { content }\end{array}$} & & \multicolumn{3}{c|}{ Atterberg limits } \\
\hline Soil name & Sand & Silt & Clay & $\mathrm{G}_{\mathrm{s}}$ & $\mathrm{W}_{\mathrm{n}}$ & $\mathrm{W}_{\mathrm{L}}$ & $\mathrm{w}_{\mathrm{p}}$ & $\mathrm{I}_{\mathrm{p}}$ \\
\hline Krakowiec clay & 5 & 38 & 57 & 2.72 & 24.0 & 65.0 & 25.0 & 40.0 \\
\hline
\end{tabular}

In order to carry out the laboratory tests both intact (undisturbed) samples and reconstituted samples were tested in the Rowe type consolidometer. The reconstituted samples were mixed with water and made into slurry at a water content of about 1.5 times 
the liquid limit, $\mathrm{w}_{\mathrm{L}}$. In order to obtain pure clay, kaolinite slumps were to be crushed and rubbed with distilled water by a mesh diameter of $0.0063 \mathrm{~mm}$. The clay slurry was left for 2 days sedimentation, then clarified water was removed from the top surface and the material was dried at $105-110^{\circ} \mathrm{C}$. Conducting tests on reconstituted samples treated as debonded material was intended to eliminate the influence of soil structure. The diameter of the cell was $75 \mathrm{~mm}$, and the initial height of samples (before the initial load) about $30 \mathrm{~mm}$. The consolidometer used in this study allows for both vertical and radial flow tests and direct permeability measurements. The pore water pressure was measured centrally on the bottom surface of the sample, at the impermeable base of cell. Before each test all the flexible leads are vented. Consolidation tests were conducted with uniform stress distribution and singlesided drainage conditions. The top boundary of the sample was made permeable by introducing filter (drain) in the form of porous bronze sintered drainage disc with a thickness of about $1.5 \mathrm{~mm}$.

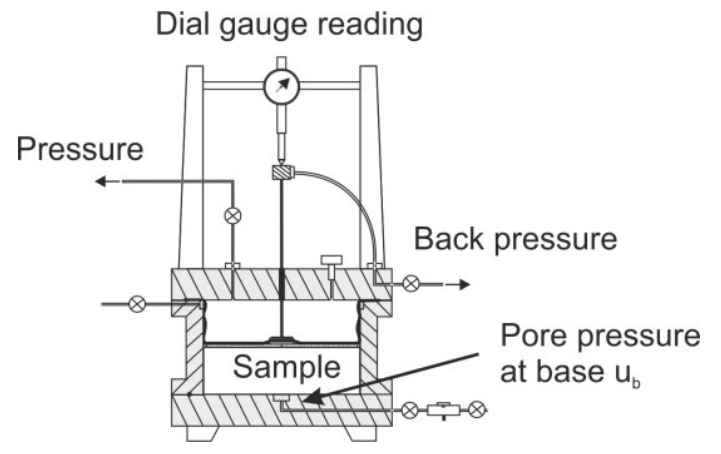

Fig. 1. Scheme of Rowe type consolidometer used in the present study.

\section{Experimental substantiation of Terzaghi's theory in terms of degree of consolidation}

\subsection{Theoretical background}

The one-dimensional differential equation that governs the consolidation and pore water pressure dissipation process is expressed as follows:

$$
\frac{\partial u}{\partial t}=c_{v} \frac{\partial^{2} u}{\partial z^{2}}
$$

where: $t$ is the time variable, $u$ is the pore water pressure and $z$ is the distance from the top of the layer subjected to consolidation.

A solution of eq. (1) for a set of boundary conditions listed in Table 3 describe how the excess pore water pressure, $u$ dissipates with time, $t$ and location, $z$ and can be obtained using Fourier series. In this type of partial differential equation, $u$ is differentiated once with respect to $t$, and twice with respect to, $z$. Above-mentioned equation is applicable to various consolidation problems with the following conservative assumptions:

(1) The soil is homogenous and fully saturated isotropic body.

(2) Both the water and soil particles are incompressible.

(3) Darcy's Law is valid for all hydraulic gradients.

(4) Compression and flow are one-dimensional (i.e. the direction of applied pressure). 
(5) Strains in the soil are infinitesimal.

(6) The coefficient of permeability, the coefficient of volume compressibility and coefficient of consolidation remain constant throughout the process.

(7) There is a unique relationship, independent of time, between the void ratio and effective stress.

(8) Immediately after loading, the excess pore water pressure is constant with depth and equal to the applied pressure.

Table 3. Boundary conditions for one-dimensional consolidation problem.

\begin{tabular}{|ll|}
\hline \multicolumn{1}{|c|}{ Boundary condition } & Mathematical expression \\
\hline 1) Complete drainage at the top of the soil layer. & $u(0, t)=0$ \\
\hline & $u(H, t)=0$ \\
2a) Complete drainage at the base of the soil layer. & $\frac{\partial u(H, t)}{\partial z}=0$ \\
2b) Base of the soil layer is impermeable. & $u(z, 0)=\Delta \sigma, u_{0}=\Delta \sigma$ \\
\hline 3) $\begin{array}{l}\text { Initial excess pore water pressure at the beginning } \\
\text { of consolidation is qual to the applied pressure. }\end{array}$ & \\
\hline
\end{tabular}

\subsubsection{Expressions for degree of consolidation}

To careful study assumption (i) experimental data were converted into well-known degrees of consolidation and compared. In general, degree of consolidation, $U$ represents a global measure of the process and can be shown to directly equal the percentage consolidation settlement [9]. In other words, this parameter defines the consolidation of the stratum as a whole and eliminates the variable of depth. At a given moment, the experimental degree of consolidation calculated based on observed deformation or changes in sample height can be written as:

$$
U_{\varepsilon, i}=\frac{h_{o}-h_{i}}{h_{o}-h_{f}}
$$

where: $h_{0}$ is the initial sample height under the analysed stress level, $h_{i}$ is the sample height in the analysed time $t$ and $h_{f}$ is the ultimate sample height at the end of excess pore water pressure dissipation under the given value of load increment.

The relationship between the degree of consolidation and dimensionless time factor, $T_{v}$ can be derived using Terzaghi's theory as:

$$
U_{\varepsilon}=1-\sum_{m=0}^{m=\infty} \frac{2}{M^{2}} \exp \left(-M^{2} T_{v}\right)
$$

where: $\mathrm{M}=(2 \mathrm{~m}+1) \pi / 2$.

On the other hand, when excess pore pressure is measured at the base of soil sample under consolidation with drainage only on the top of the sample, one can use following expression for degree of consolidation :

$$
U_{u b, i}=1-\frac{u_{o}-u_{i}}{u_{o}}
$$

where: $u_{0}$ is the pore pressure value at the initial stage of consolidation and $u_{i}$ is the pore pressure value in the analysed time, $t$. 
Theoretical degree of consolidation in this case can be derived as:

$$
U_{u b}=1-\sum_{m=0}^{m=\infty} \frac{2}{M} \sin M \exp \left(-M^{2} T_{v}\right)
$$

The dimensionless time factor, $T_{v}$ is defined by the following formula:

$$
T_{v}=\frac{c_{v} t}{H^{2}}
$$

where: $c_{v}$ is the coefficient of consolidation and $H$ is the sample height.

\subsection{Uniqueness of $U_{\varepsilon}-U_{u b}$ relationship}

Terzaghi's consolidation theory has several consequences for description of the soil behavior. According to the consolidation model a theoretical relationship correlating the degrees of consolidation determined by the two methods, based on strain measurements and pore water pressure dissipation should be unique. As can be seen from the Fig. 2 a linear relationship exist between the $U_{\varepsilon}$ and $U_{u b}$, when $U_{u b}>35 \%$ (unique linear increase of $U_{\varepsilon}$ with the increase of $U_{u b}$ ). The slope of this linear relationship specified by $\Delta U \varepsilon / \Delta U_{u b}$ was established as 0.64 . To careful study the uniqueness of the relationship, experimental data were converted into well-known degree of consolidation and compared. Note that experimental curve $U_{\varepsilon}-U_{u b}$ may lie on, above, or below the theoretical line. In other words for a given fine-grained soil any observed discrepancy from a theoretical relationship between $U_{\varepsilon}$ and $U_{u b}$ can be used as a diagnostic tool for checking Terzaghian conditions and consolidation behavior of that soil. In order to recognize the development of onedimensional strain during excess pore water pressure dissipation, experimental relationships between $U_{\varepsilon}$ and $U_{u b}$ were studied.

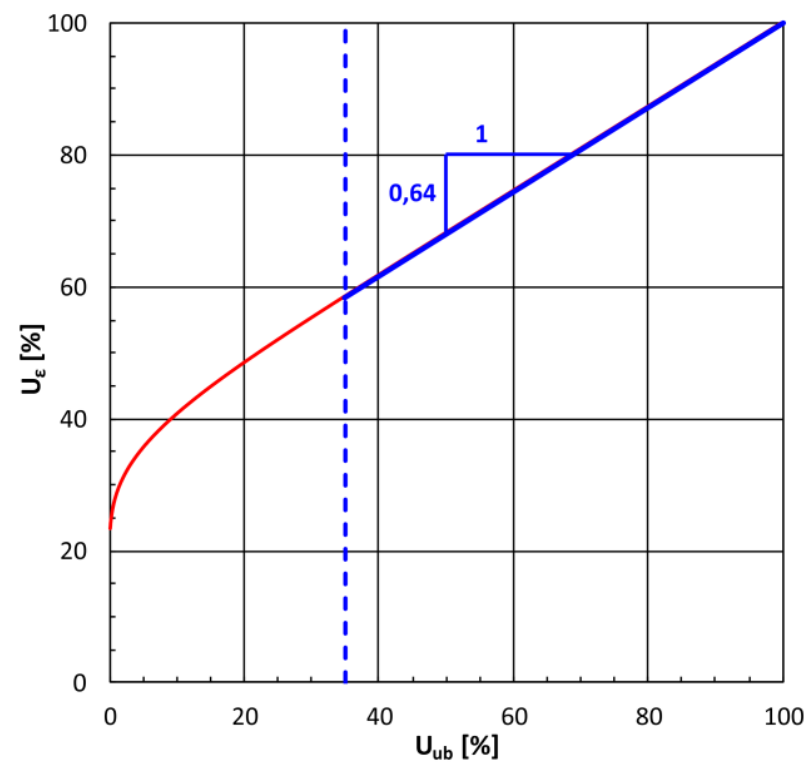

Fig. 2. Variation of theoretical average degree of consolidation and the degree of consolidation at the base. 


\subsubsection{Reconstituted samples}

Fig. 3 shows relationships between $U_{\varepsilon}$ and $U_{u b}$ and for reconstituted Krakowiec clay. The experimental observations indicate that relationship between $U_{\varepsilon}$ and $U_{u b}$ divergent from the theoretical assumption in most cases. As can be seen from a figure consolidation behavior of given soil is described by the set of nonlinear $U_{\varepsilon}-U_{u b}$ curves. In case of reconstituted samples, $U_{\varepsilon}-U_{u b}$ curves have comparable shape, although only in specific ranges of pore pressure dissipation linear development of strain was observed. Discrepancies in experimental rates of excess pore water pressure dissipation and onedimensional strain explain the obtained different characteristics of $U_{\varepsilon}-U_{u b}$ curves. Typical experimental variations of $\Delta U_{\varepsilon} / \Delta U_{u b}$ against $U_{u b}$ for reconstituted Krakowiec were shown in Fig. 4.

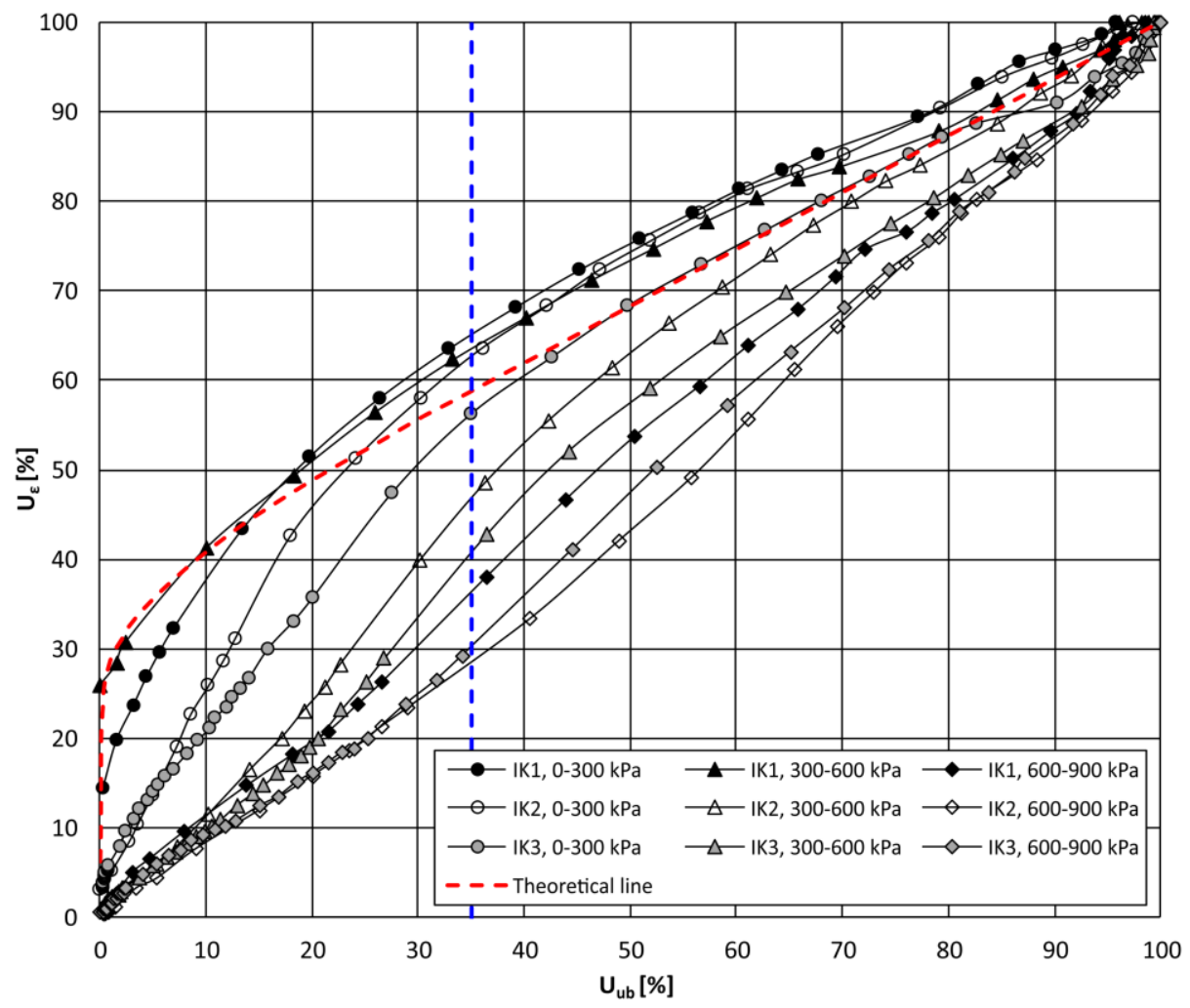

Fig. 3. Variation of experimental average degree of consolidation and the degree of consolidation at the base for reconstituted samples. 


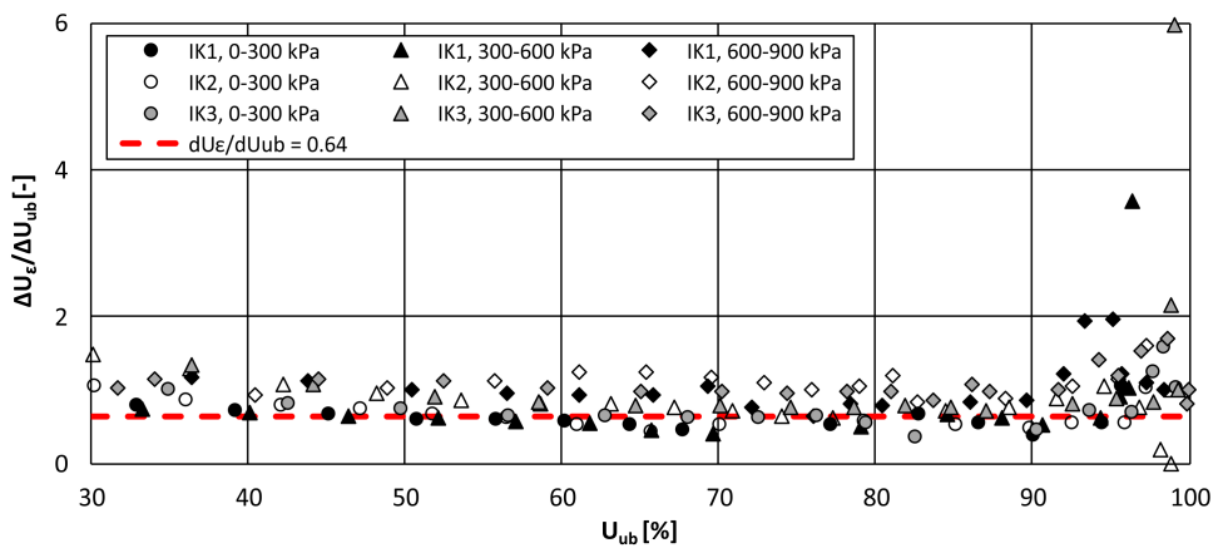

Fig. 4. Ratios of $\Delta U_{\varepsilon} / \Delta U_{u b}$ against $U_{u b}$ for reconstituted Krakowiec clay.

An analysis of the data carried about exactly in the same way as conducted by Zeng et al. [10] show that the experimental ratios of $\Delta U_{\varepsilon} / \Delta U_{u b}$ are not constant and greatly differ from each other and from the theoretical relationship after exceeding $U_{u b}>35 \%$. It is seen that experimental ratios of $\Delta U_{\varepsilon} / \Delta U_{u b}$ changing as consolidation progresses. Vast majority of those ratios were higher than theoretical constant $\Delta U_{\varepsilon} / \Delta U_{u b}=0.64$. It is also worth noting that $\Delta U_{\varepsilon} / \Delta U_{u b}$ ratios increasing with the applied pressure. However, at this stage of the research it cannot be said whether this regularity is correct for other reconstituted finegrained soils and many works are required in future for examination. Obtained results indicate one more consequence for description soil behavior. Most of experimental $U_{\varepsilon}-U_{u b}$ curves lie below theoretical line, which demonstrates faster development of onedimensional strain than dissipation of excess pore water pressure during consolidation process.

\subsubsection{Intact samples}

Fig. 5 shows relationships between $U_{\varepsilon}$ and $U_{u b}$ and for intact Krakowiec clay. The experimental curves $U_{\varepsilon}-U_{u b}$ for intact samples indicate greater non-linearity vis-a-vis reconstituted samples. Otherwise speaking experimental data is scattered which indicates non-linear development of one-dimensional strain during the dissipation of excess pore water pressure. There have also been greater discrepancies in ratios of $\Delta U_{\varepsilon} / \Delta U_{u b}$ compared to a theoretical constant $\Delta U_{\varepsilon} / \Delta U_{u b}=0.64$. 


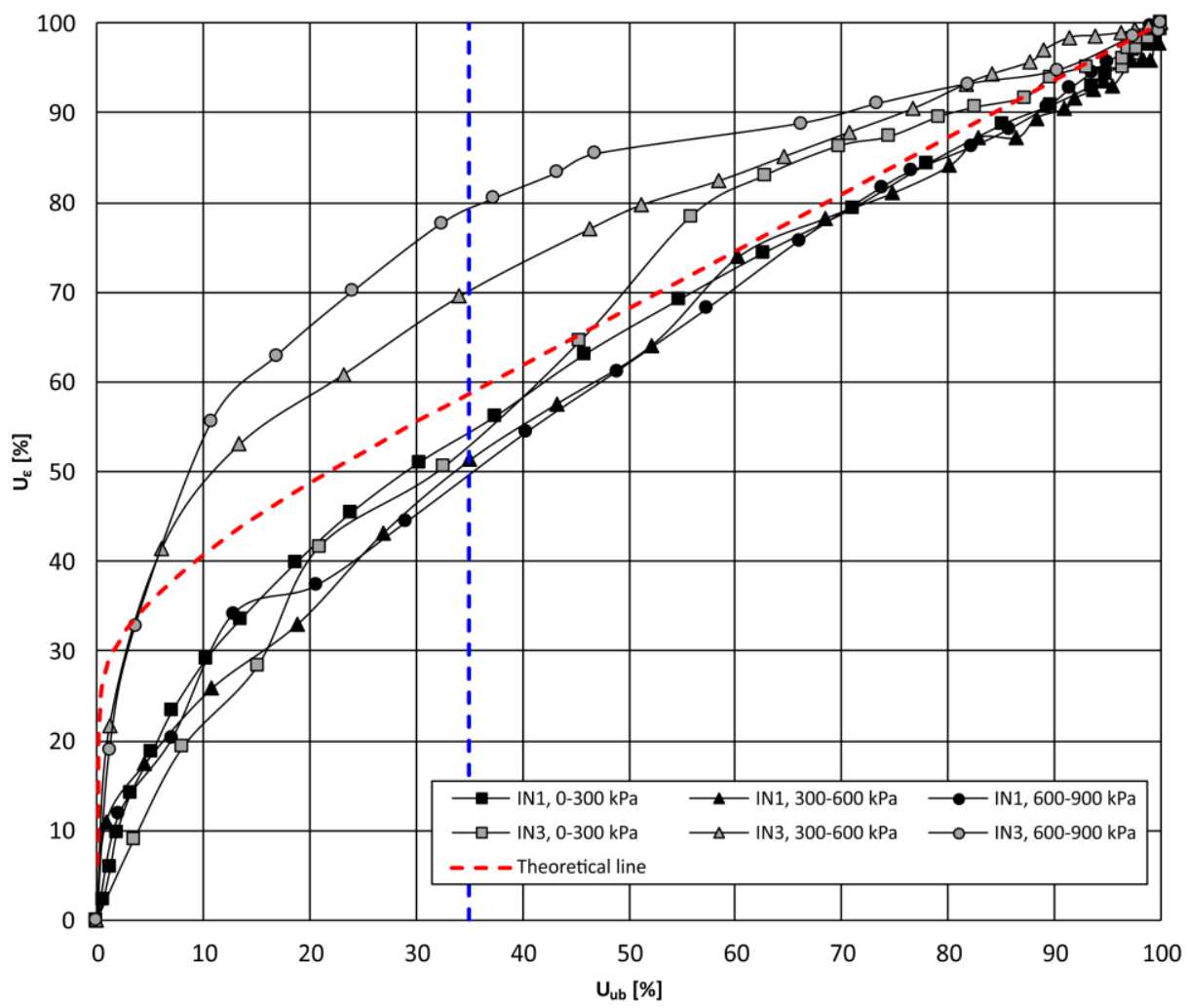

Fig. 5. Variation of experimental average degree of consolidation and the degree of consolidation at the base for intact samples.

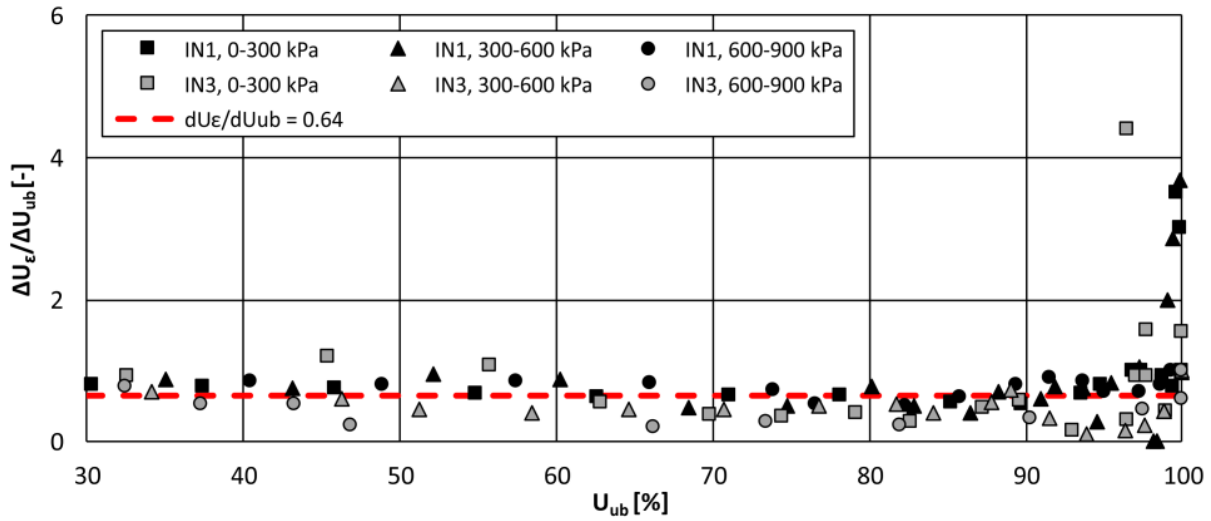

Fig. 6. Ratios of $\Delta U_{\varepsilon} / \Delta U_{u b}$ against $U_{u b}$ for intact Krakowiec clay.

\section{Conclusions}

A series of laboratory experiments were conducted to examine uniqueness of consolidation degrees relationship. Based on the results presented in these preliminary studies the following conclusions are drawn: 
1. Experimental relationship correlating degrees consolidation, determined by two methods is not unique and significantly deviates from the theoretical line.

2. Above $U_{u b}>35 \%$ the $U_{\varepsilon}-U_{u b}$ relationship is formed by a group curves corresponding to different load increments.

3. Reconstituted and intact samples of Krakowiec clay show non-linear development of one-dimensional strain during dissipation of excess pore water pressure.

\section{References}

1. S. Leroueil, Tenth Canadian geotechnical colloquium: recent developments in consolidation of natural clays. Canadian Geotechnical Journal, 25, 1, 85-107, (1988)

2. B. Wrana, Lectures on soil mechanics, (Publishing house: Politechnika Krakowska, Kraków, 2014)

3. A. Koppejan, A formula combining the Terzaghi load compression relationship and the Buisman secular time effect. Proc. 1thICSMFE, Rotterdam, 3,32-37, (1948)

4. L. Suklje, The analysis of the consolidation process by the isotaches method. Proc. 4thICSMFE, London, 1, 200-206, (1957)

5. G. Mesri, Y. Choi, The uniqueness of the end-of-primary (EOP): void ratioeffective stress relationship. Proc. 11th ICSMFE, San Francisco, 2, 587-590, (1985)

6. E.J. Haan, A compression model for non-brittle soft clay sand peat. Géotechnique, 46 1, 1-16, (1996)

7. Q. Zhu, Z-Y, Yin, P.Y. Hitcher, S.L. Shen, Nonlinear of one-dimensional creep characteristics of soft clays. Acta Geotechnica, 11, 4, 887-900, (2015)

8. C. Terzaghi, Erdbaumechanik auf Bodenphysikalischer Grundlage (Franz Deuticke, Liepzig-Vienna,1925)

9. D.W. Taylor, Fundamentals of soil mechanics (Wiley, New York, 1962)

10. L.L. Zeng, Z.S. Hong, J. Han, Experimental investigations on discrepancy in consolidation degrees with deformation and pore pressure variations of natural clays. Applied Clay Science, 152, 38-43, (2018) 